\title{
Surface enhanced infrared absorption (SEIRA) spectroscopy using gold nanoparticles on $\mathrm{As}_{2} \mathrm{~S}_{3}$ glass
}

\author{
F. Verger ${ }^{a, b, *}$, T. Pain ${ }^{a}$, V. Nazabal ${ }^{a}$, C. Boussard-Plédel ${ }^{a}$, B. Bureau ${ }^{a}$, F. Colas ${ }^{b}$, E. Rinnert ${ }^{b}$, \\ K. Boukerma ${ }^{b}$, C. Compère ${ }^{b}$, M. Guilloux-Viry ${ }^{c}$, S. Deputier ${ }^{c}$, A. Perrin ${ }^{c}$, J.P. Guin ${ }^{d}$
}

\footnotetext{
a Equipe Verres et Céramiques, UMR-CNRS 6226 Sciences Chimiques de Rennes - Université de Rennes 1, Campus de Beaulieu, 35042 Rennes cedex, France

b IFREMER, Service Interfaces et Capteurs, Département Recherches et Développements Technologiques, Centre de Brest, Technopôle Brest-Iroise, BP 70, 29280 Plouzané, France

${ }^{c}$ Equipe Chimie du Solide et Matériaux, UMR-CNRS 6226 Sciences Chimiques de Rennes - Université de Rennes 1, Campus de Beaulieu, 35042 Rennes cedex, France

' LARMAUR, Université de Rennes 1, Campus de Beaulieu, 35042 Rennes cedex, France
}

*: Corresponding author : F. Verger, email address : f.verger2@voila.fr

\begin{abstract}
:
The development of infrared sensing platform requires adapted materials. In this work, we used sputtered gold nanoparticles on a chalcogenide glass to demonstrate that these infrared materials can be used as substrate for surface enhanced infrared absorption (SEIRA) spectroscopy. The sputtering parameters were optimized to get the highest possible enhancement. To assess it, a self-assembled monolayer of 4-nitrothiophenol was used. These preliminary results are promising and pave the way for various configurations of waveguide for integrated optical components.
\end{abstract}

Keywords: Chalcogenide glass ; Sputtering Gold nanoparticles ; 4-Nitrothiopheno I; SEIRA ; Surface enhanced infrared absorption 


\section{Introduction}

Surface enhanced infrared absorption (SEIRA) was observed for the first time in 1980 by Hartstein et al. [1]. It was shown that the infrared absorption of organic compounds can be enhanced thanks to metallic nanoparticles by many orders of magnitude. Since this discovery, several studies have been published on the SEIRA effect to elucidate this phenomenon with various metals $(\mathrm{Ag}, \mathrm{Au}, \mathrm{Cu}, \mathrm{Pt})$ and molecules [2-7]. Surface plasmon resonance was found to be the origin of SEIRA even if it is not fully understood. Plasmon resonance frequency of metallic nanoparticles can be tuned in the infrared domain depending on their morphologies [8]. Thus, SEIRA have been demonstrated with various morphologies such as thin films $[4,7,9-12]$, nanorods $[13,14]$ and nanoshells $[15,16]$. Since most of the infrared signatures of organic species and biomolecules are included in the mid-infrared domain, SEIRA can be used to improve the infrared detection limits of molecules. Most reports on SEIRA [16-18] have been implemented using crystals $\left(\mathrm{CaF}_{2}, \mathrm{Ge}, \mathrm{Si}\right)$ which cannot be easily shaped into integrated optical devices devoted to mid-infrared. In this paper, chalcogenide glass is used as substrate due to its transparency in the mid-infrared. These materials can be transparent up to $20 \mu \mathrm{m}$, depending on their composition and, moreover, they can be shaped into integrated optical waveguide such as optical fibers, planar or ridge waveguides in order to fabricate some advanced optical sensing devices [19-24]. As far as we know, all the SEIRA substrates are made of crystalline material. For this first study about chalcogenide glass SEIRA substrate, the well documented fabrication method of DC sputtering was chosen as a starting point.

The monitoring of the environment requires reliable and highly sensitive devices. Many international research teams have then worked on the development of in-situ sensors for reducing the analysis time and cost. Among the different techniques, infrared spectroscopy is 
robust, versatile and reliable [25-27]. However, in coastal and estuarine natural waters, concentrations of pollutants such as hydrocarbons vary between ppb to ppm [28].

The aim of this preliminary study is to demonstrate that chalcogenide glass could be a new material for SEIRA substrate and then pave the way to the development of integrated optical waveguide for SEIRA spectroscopy. To our knowledge, this is the first observation of SEIRA on gold nanoparticles carry out in the infrared range thanks to a chalcogenide glass substrate.

\section{Materials and experimental methods}

\subsection{Synthesis of infrared glass substrate}

The infrared glass substrate used in this work was $A s_{2} S_{3}$ glass. It was synthesized in an amorphous silica tube with high purity raw As (99.999\%) and S (99.999\%) elements. Sulfur was pre-purified at $130^{\circ} \mathrm{C}$ for $19 \mathrm{~h}$ to eliminate wa ter and sulfur oxide (SOx). Arsenic and sulfur were placed in two different tubes and turbomolecular vacuum $\left(10^{-6}\right.$ Torr was used to exclude water and oxygen. During vacuum, arsenic was heated at $290^{\circ} \mathrm{C}$ for $2 \mathrm{~h}$ to remove, by volatilization, the $\mathrm{As}_{2} \mathrm{O}_{3}$ surface layer. After this step, the elements were placed under vacuum in the same silica tube which was then sealed. To exclude organic impurities, the silica tube was inserted in a distillation furnace and the temperature was increased to $750{ }^{\circ} \mathrm{C}$ and held at this temperature for $2 \mathrm{~h}$ before decreasing to room temperature. The glass was then melted in a rocking furnace at $850{ }^{\circ} \mathrm{C}$ overnight to obtain a hom ogeneous mixture and then next gradually cooled down to $500^{\circ} \mathrm{C}$ and held for $1 \mathrm{~h}$ at this temp erature in order to reduce the gas pressure in the tube. The melted glass was quickly quenched by immersing the silica tube in water $\left(20^{\circ} \mathrm{C}\right)$ and immediately placed in a furnace for ann ealing. The temperature of the furnace was a few degrees under the glass transition temperature $\operatorname{Tg}\left(192^{\circ} \mathrm{C}\right)$ and the glass was annealed for a few hours before a gradual cooling to room temperature. Annealing is necessary to reduce 
the residual stresses resulting from the cooling. The resulting glass rod was $1 \mathrm{~cm}$ in diameter and $10 \mathrm{~cm}$ in length. It was sliced into $3 \mathrm{~mm}$ thick disks using a diamond wire saw. The surface of the disks was mirror polished using alumina powder (grain size: $0.5 \mu \mathrm{m}$ ). The resulting glass disks were $2 \mathrm{~mm}$ thick.

\subsection{Gold film deposition}

Chalcogenide glass used in this study contains sulfur which ensures a good adhesion of gold on the surface via Au-S bonding and no surface treatment is required. Chalcogenide disks were sonically cleaned using acetone and isopropopanol (analytical grade, Prolabo and Carlo Erba). Gold films were then directly deposited on disks by direct current sputtering. Deposition was performed in a home-built small-sized DC sputtering device using a water-cooled coaxial cathode allowing target-substrate distance control. Deposition was performed under a pure Argon atmosphere, pumped-off with a LN2 sorption device (Riber) especially efficient against oil and water contaminations. The stainless steel substrate holder had a Thermocoax and a thermocouple built-in, and gold was sputtered at room temperature and at $180{ }^{\circ} \mathrm{C}$ taking into account the glass transition temperature $\mathrm{Tg}\left(192^{\circ} \mathrm{C}\right)$ of the chalcogenide substrate. Temperature was adjusted with the use of a KS-40 industrial temperature controller. Before deposition, the base pressure was reduced below $10^{-2}$ mbar and then increased between $5.10^{-2}$ and $6.10^{-2} \mathrm{mbar}$ after adding of argon via a needle microvalve. A number of sputtered gold films were deposited at room temperature varying the sputtering time from 30 seconds to 110 seconds with a current intensity of $0.62 \mathrm{~mA}$ and at $180^{\circ} \mathrm{C}$ with a lower current intensity of $0.14 \mathrm{~mA}$ for 30 minutes. A $2,54 \mathrm{~cm}$ in diameter target was used and was constituted of a pure gold foil (99\% purity, $0.5 \mathrm{~mm}$ thick, Goodfellow), glued with silver charged conductive epoxy glue on a copper holder screwed on the negative lead of the coaxial electrode. A small part of 
the substrate was masked with felt-tip ink to locally prevent gold deposition and then cleaned with ethanol to measure of film thickness by Atomic Force Microscopy (AFM).

\subsection{Self-assembled monolayers preparation}

The self-assembled monolayer of 4-nitrothiophenol (technical grade, Sigma-Aldrich) was prepared by soaking the gold-coated substrate in $20 \mathrm{~mL}$ of a $6.510^{-5} \mathrm{M}$ aqueous solution of 4-nitrothiophenol for $5 \mathrm{~h}$ at room temperature, and then rinsed with ethanol and dried under a flow of dry nitrogen.

\subsection{Infrared measurements}

\subsubsection{Optical properties}

The infrared transmission spectra of the chalcogenide glass As2S3 and the optical extinction spectra of gold films were acquired with two spectrometers. The extinction spectra were recorded by the measurement of absorbance which represent $\log (1 / T)$. For the visible to nearinfrared region (0.6-2 $\mu \mathrm{m})$, measurements were made by a UV-visible-NIR Perkin-Elmer lambda 1050 spectrometer. And for the near to mid-infrared range $(2-14 \mu \mathrm{m})$, measurements were performed by a Fast Fourier Transformed Spectrometer (FFTS, Bruker VECTOR 22, Bruker optics Inc, Germany). All the spectra were recorded using a co-addition of 30 scans at $4 \mathrm{~cm}^{-1}$ in transmission mode. The background spectrum of the atmosphere was measured as a single beam and was used as reference.

\subsubsection{SEIRA spectra}


The SEIRA spectra of 4-nitrothiophenol on gold films were recorded on FTIR Thermo Nicolet spectrometer in transmission mode, using a DTGS detector, a resolution of $4 \mathrm{~cm}^{-1}$ and a co-addition of 256 scans. The background spectrum of atmosphere was measured as a single beam and was used as reference. A baseline correction was performed to eliminate the absorption of the substrate covered by gold nanoparticles in order to show the absorption of 4nitrothiophenol. The SEIRA spectra are represented according to the thickness as previously reported by others authors $[3,5,7]$.

\subsection{Atomic Force Microscopy}

Gold film morphology and thickness were investigated by Atomic Force Microscopy (Dimension 3100, Nanoscope V, Digital Instruments, Santa Barbara CA, USA), operated in tapping mode using a doped silicon tip (BS-TAP300Al) with an average radius of less than $10 \mathrm{~nm}$ and a resonant frequency of $300 \mathrm{kHz}$. The AFM was calibrated using a $21.5 \pm 1 \mathrm{~nm}$ step height $Z$ axis calibration grating (TGZ1 from NT-MDT). The mean thickness was measured thanks to a mark left by a permanent marker on the substrate surface prior to gold deposition. After which it was dissolved away with ethanol.

\subsection{Conductivity of gold film}

The conductivity of the gold films was checked with an ohmmeter. The two tips were placed in contact with the gold surface on different areas and were separated by few millimeters. Gold film was considered to be discontinuous when resistance higher than $1000 \mathrm{~W}$ was measured and the ohmmeter was made a sound. 


\section{Results and discussion}

\subsection{Optical transmission of $\mathrm{As}_{2} \mathrm{~S}_{3}$ glass}

The transmission spectrum of a representative $\mathrm{As}_{2} \mathrm{~S}_{3}$ glass disk is shown in Fig.1.

In terms of bulk glass, the optical transparency of the $\mathrm{As}_{2} \mathrm{~S}_{3}$ glass extends from $0.7 \mu \mathrm{m}$ to $10 \mu \mathrm{m}$, in Fig. 1. The lower limit of the transmission is due to the electronic band gap of the glass where the electronic lone-pair $p$ states forming the top part of the valence band play an important role. In the infrared region, the transparency is limited by low energy phonons. It's worth noting that most of the infrared signatures of organic species or biomolecules are included in this spectral domain. This chalcogenide glass is suitable for infrared detection. Moreover, it can be shaped into sophisticated optical devices such as optical fibers, planar or ridge waveguides. First of all, one has to demonstrate the feasibility of the SEIRA effect on polished vitreous plates of $\mathrm{As}_{2} \mathrm{~S}_{3}$.

\subsection{Atomic Force Microscopy characterization of $\mathrm{As}_{2} \mathrm{~S}_{3}$ glass disk surface and gold films}

The roughness of the polished $\mathrm{As}_{2} \mathrm{~S}_{3}$ glass disk surface and the topography of sputtered gold films were characterized by Atomic Force Microscopy (AFM). Fig. 2 shows AFM pictures of the polished substrate surface before (a) and after the sputtering of gold (b, c, d) and the crosssection profile of a gold film (e, f).

As seen from Fig. 2a, the surface of the substrate remains rough even after polishing. The surface roughness computed over $1 \times 1 \mu \mathrm{m}^{2}$ area is about $3.5 \mathrm{~nm}$. The scratches are about $1 \mathrm{~nm}$ 
in depth. Note that a smooth surface is essential to ensure the homogeneity of the metal film growth [29]. As shown in Fig. 2b, 2c and 2d, nanoparticles cover the whole surface of the vitreous substrate after gold sputtering. The film is made up of densely packed gold nanoparticles. At room temperature, the diameter of these gold islands is around $17 \pm 4 \mathrm{~nm}$ (Fig. 2c) but because of the AFM tip curvature radius the real diameter might be slightly less than $17 \mathrm{~nm}$. Conductivity tests show that gold films are non-conducting until 80 seconds of sputtering at room temperature and also for 30 minutes of sputtering at lower current intensity at room temperature and at $180^{\circ} \mathrm{C}$. For non-conducting gold films, gold nanoparticles are supposed to be separated. The distance between each nanoparticle, called air gap, could not be directly measured because of the AFM tip size of about $10 \mathrm{~nm}$ and the density of coverage. The mean gap between the particles is supposed to be less than $10 \mathrm{~nm}$. Furthermore, Scanning Electron Microscope (SEM) images did not show the nanoparticles. They are then below the resolution of the microscope. The nanoparticles are supposed to be separated by only few nanometers. For the sputtered gold film deposited at $180^{\circ} \mathrm{C}$ (Fig. 2d), the islands seem to be larger with a diameter of about $34 \pm 8 \mathrm{~nm}$.

Fig. $2 \mathrm{e}$ and $2 f$ show the AFM picture and section profile of a gold film sputtered at room temperature for 70 seconds. The step between the uncovered $\mathrm{As}_{2} \mathrm{~S}_{3}$ substrate surface (right) and the gold surface (left) is clearly visible. Using such a profile, the average height of each step has been evaluated versus the deposition time and reported in Table 1.

The results show an increase in gold thickness with the sputtering time. The percolation threshold is reached between 80 seconds and 110 seconds of sputtering. Gold islands touch each other and the gold film becomes conductive. 


\subsection{Extinction of discontinuous gold island films}

The optical extinction of a metallic nanoparticle represents the scattering of light and the absorption due to surface plasmons collective oscillations [30, 31]. Fig. 3a and 3b show the optical extinction spectra of a series of gold island films sputtered at room temperature with various thicknesses on $\mathrm{As}_{2} \mathrm{~S}_{3}$ glass and for 30 minutes at room temperature and at $180{ }^{\circ} \mathrm{C}$, respectively.

Fig. $3 a$ shows that the extinction becomes broader and more intense as the thickness of the films increases. Such a kind of SEIRA substrate does not present a well-defined plasmon band and the same dependence of extinction on the thickness of silver film on $\mathrm{CaF}_{2}$ substrate $[32,33]$ and gold films on silanized glass [33] has already been reported. For isolated gold spherical nanoparticles with diameter ranges from $10 \mathrm{~nm}$ to $30 \mathrm{~nm}$, the extinction is located in the visible range at around $520 \mathrm{~nm}$ and is quite sharp [8, 30, 34, 35]. When several spherical nanoparticles are very close to each other, the optical extinction becomes broader and shifts to longer wavelengths (red-shift) because of an inter-particle coupling [31], as also explained by Gans theory. The plasmon resonance in the infrared is supposed to happen because of the coupling between nanoparticles that requires an air gap of few nanometers.

Also, the optical extinction of gold films depends on sputtering temperature, as observed in Fig. 3b. With increasing temperature of the substrate during sputtering, the intensity of extinction becomes weaker and a shift to shorter wavelengths is observed (blue shift). In fact, higher temperature of the substrate enables the Au adsorbed atoms to move more freely over the surface of the substrate during the deposition to interact among themselves forming bigger islands by agglomeration. Consequently, the air gap between the nanoparticles can increase leading to the disappearance of inter-particle coupling, as already mentioned in many reports [9, 
33, 36, 37]. The correlation between extinction spectra and SEIRA spectra will be detailled later in this article.

\subsection{SEIRA spectra of 4-nitrothiophenol}

As in previous studies $[3,5]$, a monolayer of 4 -nitrothiophenol was used to assess the SEIRA phenomenon. The infrared spectrum of 4-nitrothiophenol monolayers and randomly oriented are well known. Fig. 4 shows the infrared transmission spectrum of randomly oriented 4-nitrothiophenol on the chalcogenide substrate.

The band assignment is made according to the work of Zhang and Imae [3]. The strongest bands are located at $1336 \mathrm{~cm}^{-1}$ and $1512 \mathrm{~cm}^{-1}$ and correspond to $\mathrm{NO}_{2}$ symmetric and antisymmetric stretching modes, respectively. Regarding SEIRA, we focussed our attention on the $1300 / 1530 \mathrm{~cm}^{-1}$ region.

The infrared spectra of 4-nitrothiophenol on sputtered gold films on $\mathrm{As}_{2} \mathrm{~S}_{3}$ substrates at room temperature and at $180^{\circ} \mathrm{C}$ are shown in Fig. $5 a$ and $5 b$, respectively.

First of all, a strong band is observed at $1500 \mathrm{~cm}^{-1}$ which is attributed to normal $\mathrm{CS}_{2}$ residual impurities in the $\mathrm{As}_{2} \mathrm{~S}_{3}$ bulk glass (Fig. $5 \mathrm{a}$ and $5 \mathrm{~b}$ ). This band is observed in transmission mode without gold nanoparticles on the substrate. Its intensity depends on the impurity concentration in the substrate. Moreover, the SEIRA effect is mainly located between the gold nanoparticles . Thus, no enhancement of the CS2 impurities absorption is expected.

On the other hand, the intensity of the $\mathrm{NO}_{2}$ symmetric stretching band at $1336 \mathrm{~cm}^{-1}$ is clearly dependent on the thickness of the gold island films (Fig. 5a). Discontinuous gold films enhance this infrared absorption band compared to a continuous gold film with a thickness of $31 \pm 4 \mathrm{~nm}$. 
Enhancement is observed only with discontinuous gold films because of the gap between nanoparticles whereas they are connected each other in a continuous film. As previously observed by Osawa [7], there is a optimal film thickness for enhancement which is not associated with the stronger extinction. In his paper, the optimal thickness of a silver island film is $10 \mathrm{~nm}$ because they become nearly continuous with the increase of thickness. In this paper, the optimal thickness is $16 \pm 1 \mathrm{~nm}$ and shows the best enhancement, about 10 fold higher. The gold film with a $30 \pm 3 \mathrm{~nm}$ is nearly continuous and the enhancement is lower about 6 fold higher.

A slight shift, about $5 \mathrm{~cm}^{-1}$, in the frequency of the $\mathrm{NO}_{2}$ symmetric band between gold films is also observed and is not explained for the moment. Also, the SEIRA effect leads to band asymmetry as previously observed $[4,5,38]$.

Whatever the gold films, the band associated with the antisymmetric stretching mode of the nitro group is not observed as previously reported by Bjerke and Griffiths [5] and was explained by surface selection rules. Indeed, on a gold surface, thiol compounds are known to be linked to Au by the SH group via Au-S bonding. A monolayer of 4-nitrothiophenol is formed by molecules oriented perpendicularly on a gold surface with the nitro group on top. The dipole moment of the $\mathrm{NO}_{2}$ symmetric and antisymmetric stretching are perpendicular and parallel to the gold surface, respectively. Surface plasmons of gold islands are excited by the electromagnetic field of incident light. A local electric field is generated around gold nanoparticles and is perpendicular to the gold surface at every point. In surface selection rules, only groups with their dipole moments parallel to the electric field lines are enhanced and are SEIRA active. For the $\mathrm{NO}_{2}$ group of 4-nitrothiophenol, only the symmetric stretching mode is parallel to the electric field lines and is the only one enhanced and observed. In comparison, the SEIRA spectra of randomly oriented 4-nitrothiophenol show both symmetric and antisymmetric stretching modes. In addition, the dependence of the SEIRA spectra on the increasing temperature of the substrate during sputtering has also been investigated (Fig. 5b). The results show that the 
intensity of the $1336 \mathrm{~cm}^{-1}$ band for a gold film sputtered at room temperature is four fold higher than a gold film sputtered at $180{ }^{\circ} \mathrm{C}$. As previously, the $\mathrm{NO}_{2}$ antisymmetric absorption band is not observed. A reduced coupling between the island particles is involved in the case of our gold deposition on $\mathrm{As}_{2} \mathrm{~S}_{3}$ glass substrates at $180^{\circ} \mathrm{C}$. In fact, as the streng th of a local electric field generated by the interaction of metal nanoparticles depends strongly on the distance between them [31, 39], the SEIRA performance is also sharply affected and the enhancement of absorption decreases with inter-particle gap increase.

\section{Conclusion}

Surface enhanced infrared absorption (SEIRA) spectroscopy was investigated using gold nanoparticles deposited by DC sputtering on $\mathrm{As}_{2} \mathrm{~S}_{3}$ glass. For this first study on chalcogenide glass based SEIRA substrate, this well documented fabrication method was chosen as a starting point. Many other fabrication processes were reported and some demonstrate much higher enhancement factor. The highest enhancement factor ever reported is 300000 [14]. It was achieved using nanoantennas synthesized by electron beam lithography. The high chemical and physical stability of chalcogenide glass would enable one to adapt some of these fabrication processes to these materials. It would then be possible to develop integrated optical waveguide for very sensitive SEIRA spectroscopy.

\section{Acknowledgements}

This work is supported by the French National Center for Scientific Research (CNRS) and the French Research Institute for Exploitation of the Sea (IFREMER). 


\section{References}

[1] A. Hartstein, J. R. Kirtley, and J. C. Tsang, Physical Review Letters 45 (1980) 201-204.

[2] Y. Nishikawa et al., Vibrational Spectroscopy 6 (1993) 43-53.

[3] Z. Zhang, and T. Imae, Journal of Colloid and Interface Science 233 (2001) 99-106.

[4] H. Seki et al., Surface Science 506 (2002) 23-32.

[5] Bjerke et al., Surface-enhanced infrared absorption spectroscopy of p-nitrothiophenol on vapor-deposited platinum films (Society for Applied Spectroscopy, Frederick, MD, ETATS-UNIS, 2002), Vol. 56 1275-1280.

[6] Y. Suzuki et al., in 9th International Conference on Vibrations at Surfaces (VAS9) (Elsevier Science Bv, Hayama, Japan, 1998), pp. 136.

[7] M. Osawa, and M. Ikeda, Journal of Physical Chemistry 95 (1991) 9914-9919.

[8] S. Lal, S. Link, and N. J. Halas, Nat Photon 1 (2007) 641-648.

[9] Y. Suzuki et al., Thin Solid Films 515 (2007) 3073-3078.

[10] J. M. Delgado, J. M. Orts, and A. Rodes, Electrochimica Acta 52 (2007) 4605-4613.

[11] D. Enders et al., Surface Science 600 (2006) 305-308.

[12] T. Kamata et al., Langmuir 3 (1987) 1150-1154.

[13] A. Pucci et al., Physica Status Solidi B-Basic Solid State Physics 247 (2010) 20712074.

[14] F. Neubrech et al., Physical Review Letters 101 (2008) 157403(1)-157403(4).

[15] H. Wang, J. Kundu, and N. J. Halas, Angewandte Chemie-International Edition 46 (2007) 9198-9202.

[16] J. Kundu et al., Chemical Physics Letters 452 (2008) 115-119.

[17] K. Ataka, and J. Heberle, Analytical and Bioanalytical Chemistry 388 (2007) 47-54.

[18] M. Osawa et al., Applied Spectroscopy 47 (1993) 1497-1502.

[19] B. Bureau et al., Journal of Non-Crystalline Solids 345 (2004) 276-283.

[20] J. Charrier et al., Journal of Applied Physics 104 (2008) 073110(1)-073110(8).

[21] D. Le Coq et al., Comptes Rendus Chimie 5 (2002) 907-913.

[22] J. Le Person et al., Sensors and Actuators B-Chemical 130 (2008) 771-776.

[23] B. Bureau et al., Molecules 14 (2009) 4337-4350.

[24] X. H. Zhang et al., Chemistry-a European Journal 14 (2008) 432-442.

[25] B. Pejcic, M. Myers, and A. Ross, Sensors 9 (2009) 6232-6253.

[26] B. Mizaikoff, Measurement Science \& Technology 10 (1999) 1185-1194.

[27] B. Mizaikoff, Water Science and Technology 47 (2003) 35-42.

[28] E. Manoli, and C. Samara, Trac-Trends in Analytical Chemistry 18 (1999) 417-428.

[29] Y. L. Lee, and J. R. Maa, Journal of Materials Science Letters 10 (1991) 1398-1400.

[30] P. K. Jain et al., Journal of Physical Chemistry B 110 (2006) 7238-7248.

[31] F. Le et al., ACS Nano 2 (2008) 707-718.

[32] M. Osawa, Bulletin of the Chemical Society of Japan 70 (1997) 2861-2880.

[33] I. Doron-Mor et al., Chemistry of Materials 16 (2004) 3476-3483.

[34] P. K. Jain et al., Plasmonics 2 (2007) 107-118.

[35] M. Hu et al., Chemical Society Reviews 35 (2006) 1084-1094.

[36] T. Karakouz et al., Chemistry of Materials 21 (2009) 5875-5885.

[37] F. Meriaudeau et al., Sensors and Actuators B-Chemical 69 (2000) 51-57.

[38] D. A. Heaps, and P. R. Griffiths, in 6th Australian Conference on Vibrational

Spectroscopy (ACOVS6) (Elsevier Science Bv, Sydney, AUSTRALIA, 2005), pp. 221.

[39] J. M. McMahon et al., Analytical and Bioanalytical Chemistry 394 (2009) 1819-1825. 
Fig. 1. Transmission spectrum of $\mathrm{As}_{2} \mathrm{~S}_{3}$ bulk glass with thickness of about $2 \mathrm{~mm}$.

Fig. 2. AFM pictures of polished $A s_{2} S_{3}$ surface (a), covered by gold nanoparticles at room temperature $(b, c)$ and at $180^{\circ} \mathrm{C}(\mathrm{d})$, cross-section profile of a gold film $(e, f)$. All pictures are in phase contrast excepted Fig. $2 f$.

Fig. 3. Extinction spectra of sputtered gold films with various thicknesses on $\mathrm{As}_{2} \mathrm{~S}_{3}$ glass at room temperature (a) and for 30 minutes of sputtering at room temperature and at $180{ }^{\circ} \mathrm{C}$ (b). Fig. 4. Infrared spectrum of randomly oriented 4-nitrothiophenol on $\mathrm{As}_{2} \mathrm{~S}_{3}$ substrate.

Fig. 5. Infrared transmission spectra of 4-nitrothiophenol monolayers on sputtered gold island films of various thicknesses at room temperature (a) and for 30 minutes of sputtering at room temperature and $180^{\circ} \mathrm{C}(\mathrm{b})$.

Table 1. Change of gold film thickness with the sputtering time and conductivity. The pressure of Argon was $6.10^{-2}$ mbar with a current intensity of $0.62 \mathrm{~mA}$. 


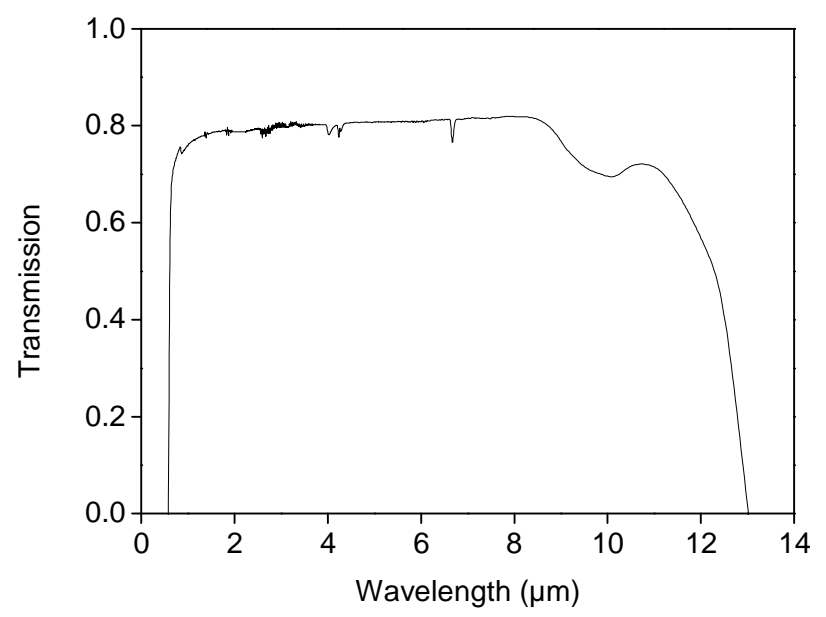

Figure 1 


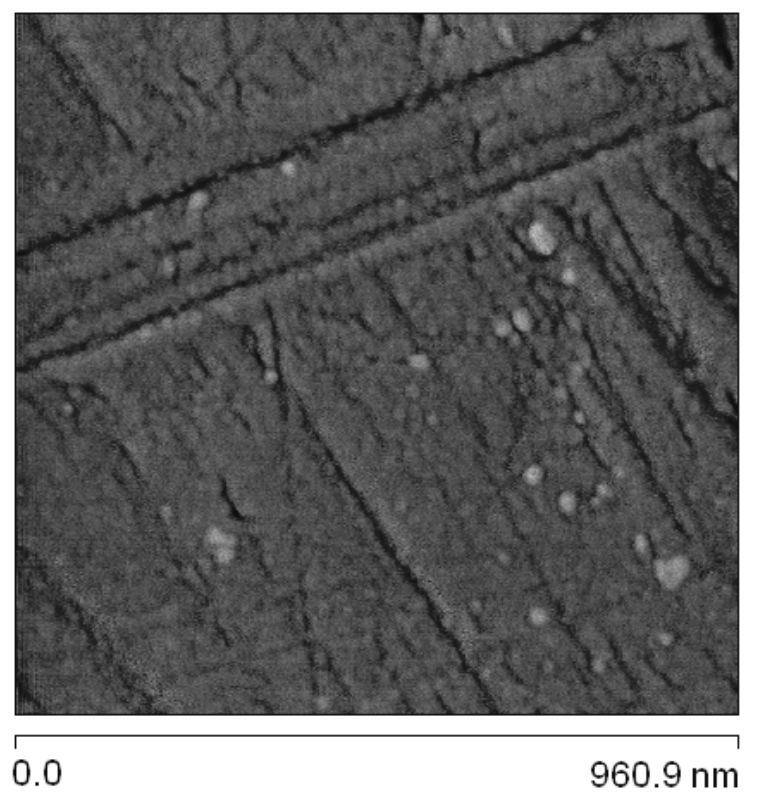

Figure 2a 


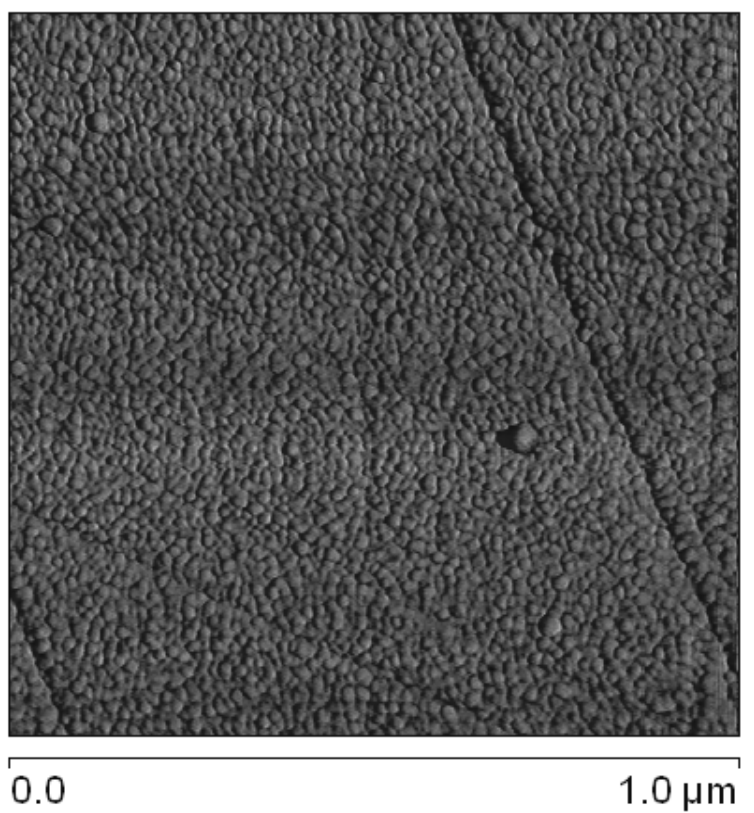

Figure $2 b$ 


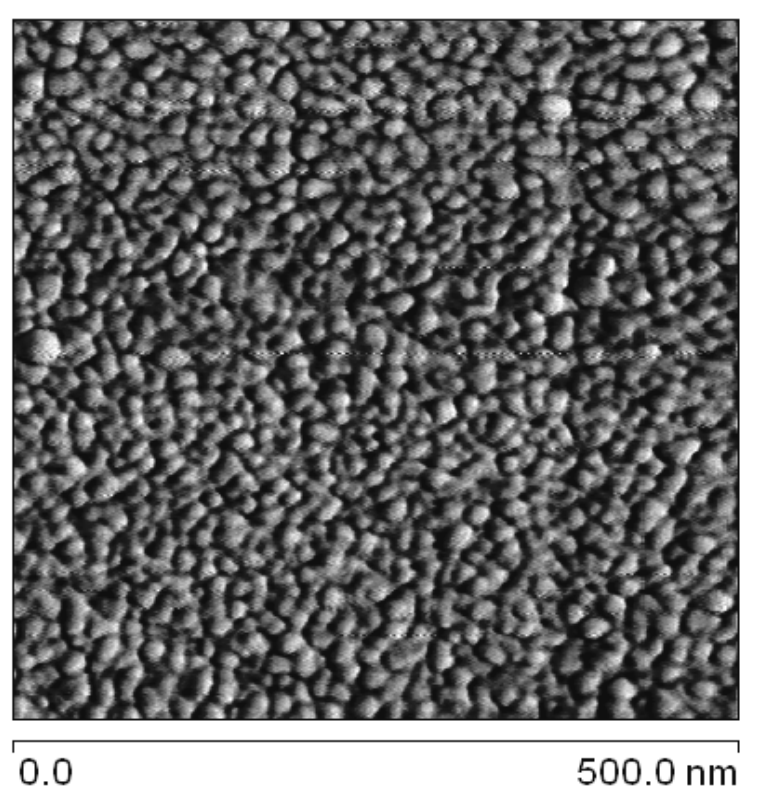

Figure 2c 


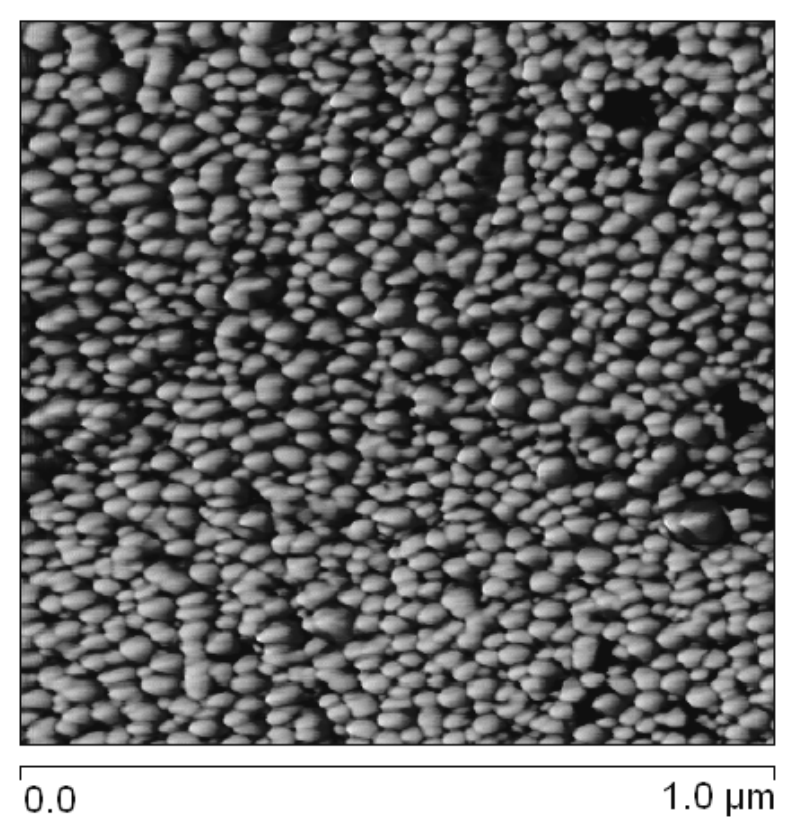

Figure 2d 


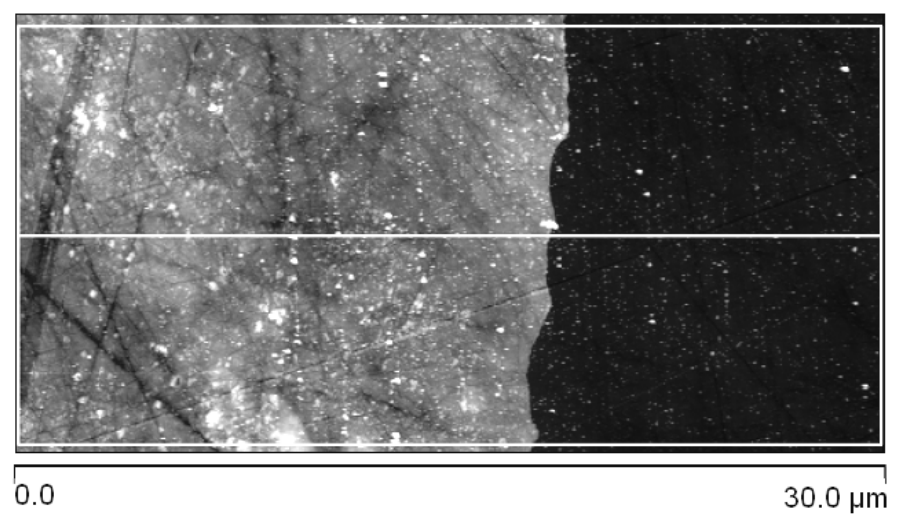

Figure 2e 


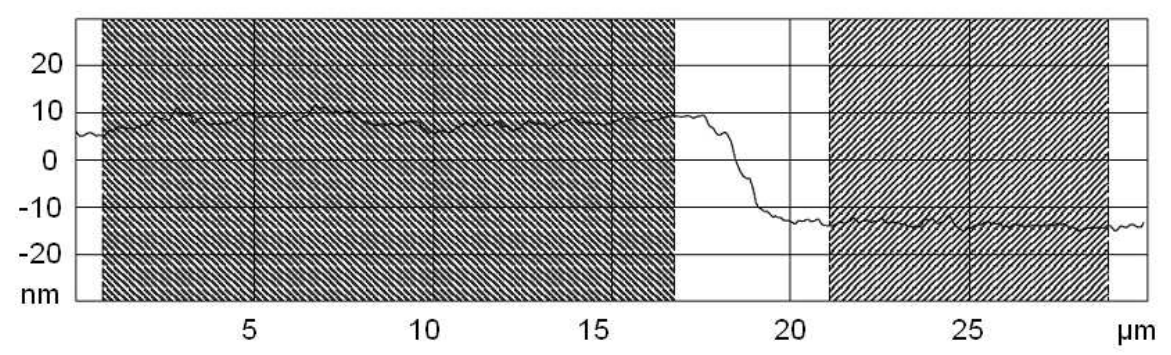

Figure $2 f$ 


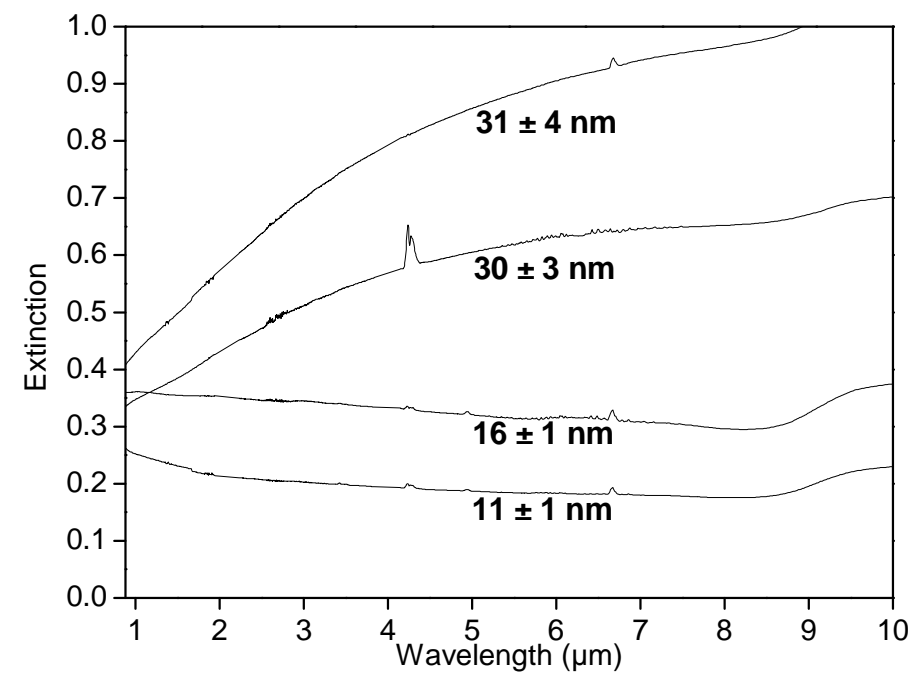

Figure $3 a$ 


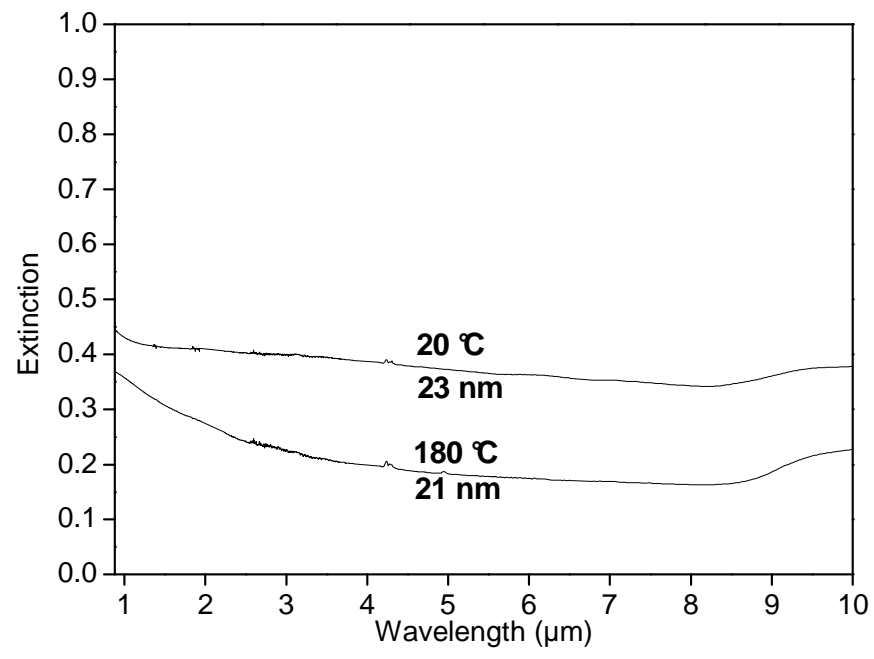

Figure $3 b$ 


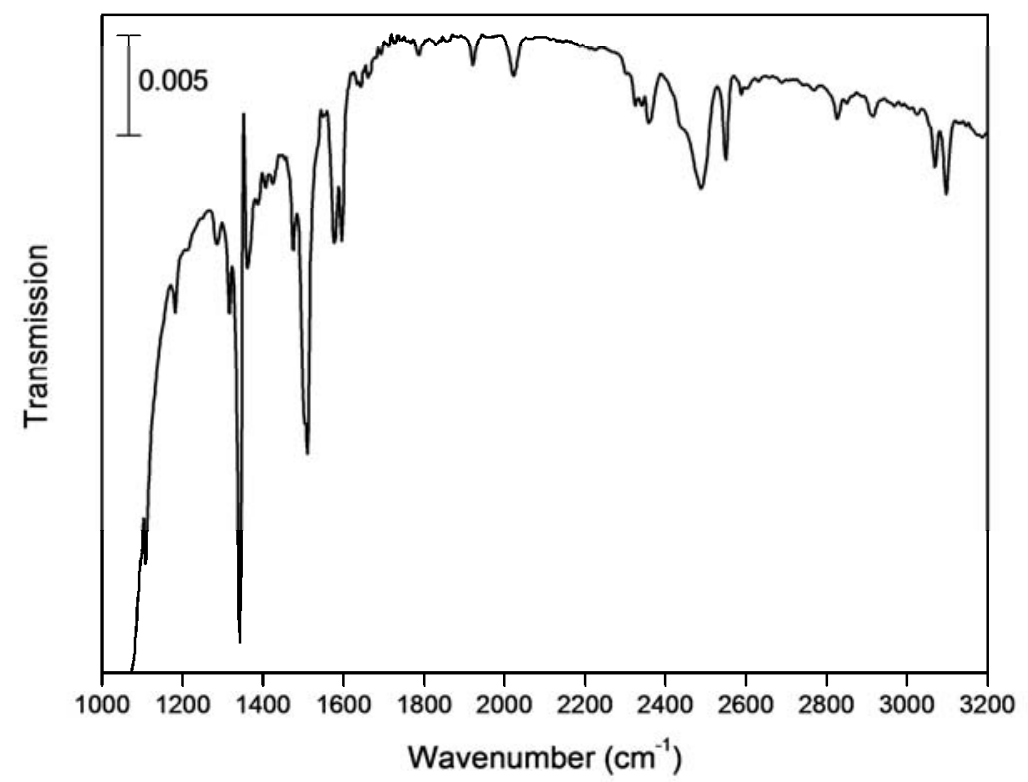

Figure 4 


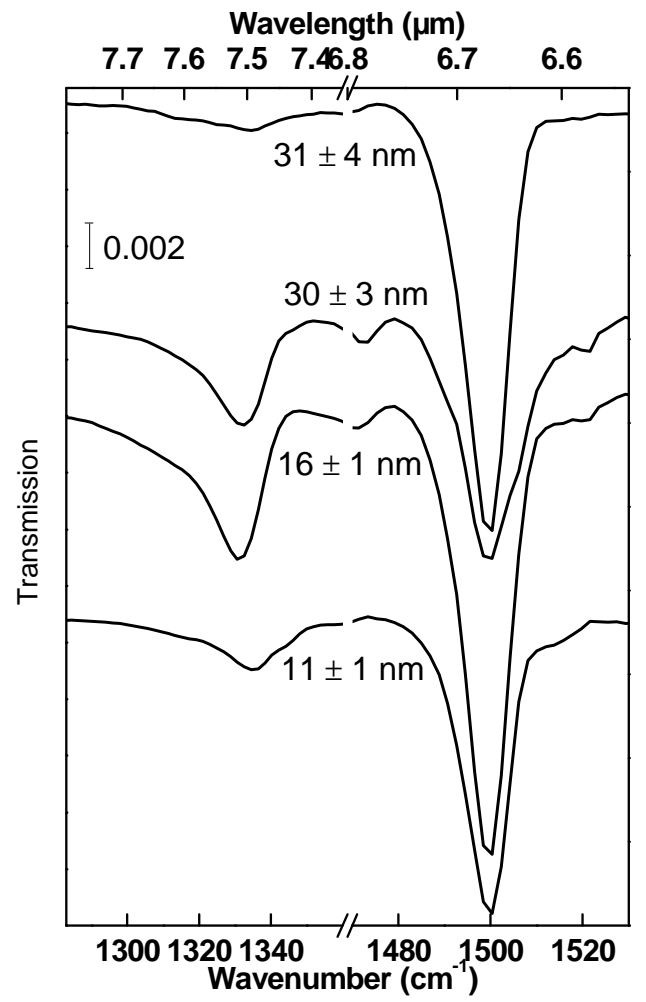

Figure 5a 


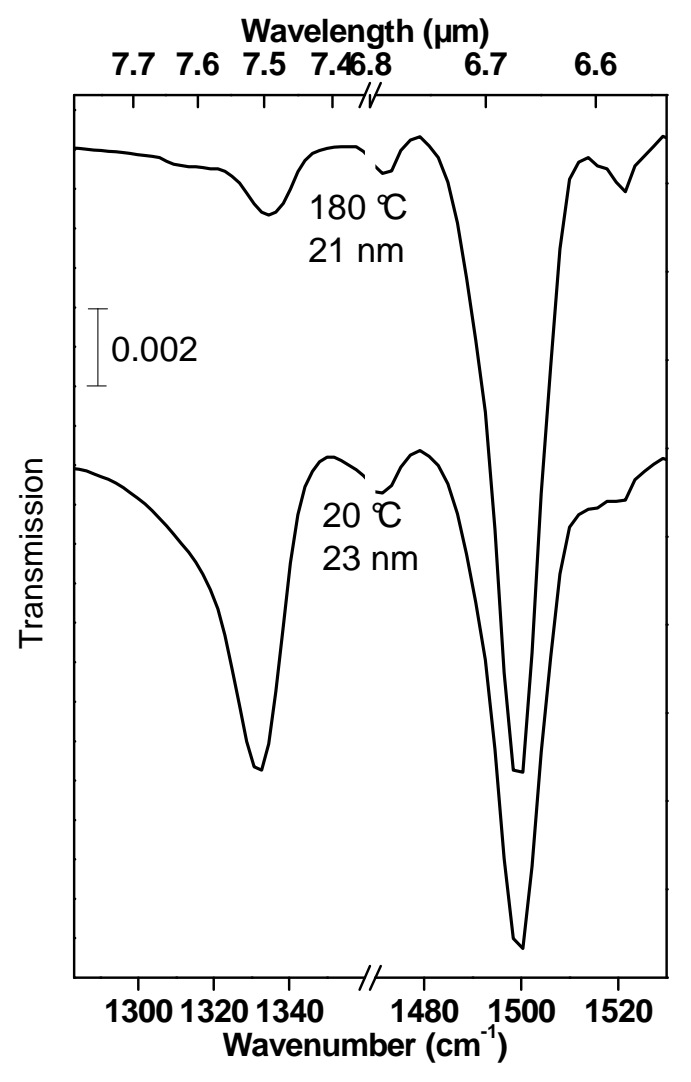

Figure 5b 
Table 1

\begin{tabular}{|llll|}
\hline $\begin{array}{l}\text { Sputtering } \\
\text { time (sec.) } \\
\text { at } 6.10^{-2} \text { mbar } \\
\text { and } 0.62 \mathrm{~mA}\end{array}$ & $\begin{array}{l}\text { Gold film } \\
\text { thickness }(\mathrm{nm})\end{array}$ & $\begin{array}{l}\text { Standard } \\
\text { deviation (nm) }\end{array}$ & Conductivity \\
\hline 30 & 11 & 1 & Non-conductive \\
60 & 16 & 1 & Non-conductive \\
80 & 30 & 3 & Non-conductive \\
110 & 31 & 4 & Conductive \\
\hline
\end{tabular}


Frederic Verger received a Master's degree in marine chemistry from the University of Brest (France), in 2007. He is currently a PhD candidate at the University of Rennes (France). His research is focused on surface enhanced infrared absorption spectroscopy devoted to the infrared detection of hydrocarbons in sea water.

Thierry Pain is glassblower of scientific glassware. From 1990 to 1992, he worked at the BAQUERE et V.E.R.A.L society (Paris, France). In 1993, he joined the University of Rennes (France). He is the co-author of 5 papers and also makes precision optical polishing.

Virginie Nazabal got the PhD degree in Solid State Chemistry and Materials Sciences from the University of Bordeaux (France) in 1999. She joined in 2000 the Functional Glass Group at NIMS (Japan) for a post-doctoral position. Since 2001, she belongs to the CNRS. Within the Glasses and Ceramics team at the University of Rennes (France), she specialized in the field of thin films for optics with nearly 70 publications as author or co-author and several oral and invited contributions in international conferences. She received in 2010 a bronze medal of CNRS for her research in the field of materials chemistry.

Dr. Catherine Boussard-Pledel, defended her $\mathrm{PhD}$, focused on glasses in the system B-O-F, at the University of Rennes (France) in 1997. Since 1999, she is engineer at the CNRS, in the Glasses and Ceramics group of the Chemical Sciences Center in Rennes. She is in charge of the development of fibers (multimode, single mode) and she works on the development of infrared sensors having applications in biomedicine, environment and spatial areas. She is involved in several international research programs. She is the author and co-author of about 70 publications and 2 patents. 
Professor Bruno Bureau defended his $\mathrm{PhD}$ in 1998 from the University of Maine (France) on "structural studies of fluoride glasses by solid state NMR". He was appointed assistant professor in 1999 and professor in 2006 at the Glasses and Ceramics laboratory at the University of Rennes (France). He is in charge of the "infrared optical sensors" group. He is the author or coauthor of about 100 papers in the field of non oxide glasses, infrared sensing, material and glass science. He is appointed to the "Institut Universitaire de France" in 2011.

Florent Colas received, in 2004, an engineer degree from the Optical Institute (Palaiseau, France) and an Msc of optics and photonics from Imperial College (London, UK). In 2005, he joined the Interfaces and Sensors laboratory at Ifremer (Brest, France). Since then, he has been working on optical sensors for the marine environment. His main activity is on underwater optical sensors based on Surface Plasmon Resonance, Surface Enhanced Raman Scattering and Surface Enhanced IR Absorption. He is the co-author of 4 publications.

Emmanuel Rinnert got a PhD degree in physical chemistry in 2004 from the University of Nancy (France). He works on vibrational spectroscopies since 9 years. In 2005, he joined the Interfaces and Sensors group at Ifremer where he is research engineer in analytical chemistry. He is responsible for the development of Raman spectroscopy for in situ marine applications including surface enhanced Raman scattering analysis. He is author and co-author of 9 publications involving infrared or Raman spectroscopy development.

Kada Boukerma received the $\mathrm{PhD}$ degree in physical chemistry of materials from University Denis Diderot (Paris, France) in 2005. After 4 years of postdoctoral researcher at Pierre and Marie Curie University and University of Pau, he joined IFREMER in 2010 and his research 
interests include biofunctionalization of metallic surfaces, antifouling surfaces and surface analysis. He is the author and co-author of 10 publications.

Chantal Compere received her PhD in chemistry from Louis Pasteur University (Strasbourg, France) in 1984. She worked for 4 years at the National Research Council of Canada in the field of electrochemistry and corrosion and after, she has joined the University of Laval (Quebec, Canada). In 1992, she joined Ifremer and she is presently responsible for the Interfaces and Sensors laboratory at Ifremer (Brest, France). The laboratory conducts research on biosensors, sensors for in-situ monitoring in natural seawater and antifouling treatments. She is the author and co-author of 60 publications, 14 book chapter, more than 100 conferences and 2 CD roms.

Maryline Guilloux-Viry received the PhD degree in physics from the University of Rennes (France) in 1991. She was researcher at the CNRS from 1991 to 2005 at the laboratory of Solid State Chemistry and Materials. She became Professor in 2005 at the University of Rennes. She is now in charge of managing the group "Solid State Chemistry and Materials". Her main research field concerns the synthesis and the characterization of thin films, especially epitaxial growth, and the characterization of thin films of various materials. She is the co-author of about 150 papers in the field of thin films.

Stephanie Deputier received the Ph.D. degree in chemistry from the University of Rennes (France), in 1992. Since 1994, she is an Assistant Professor at the laboratory of Solid State Chemistry and Materials, from the University of Rennes. Her research activities currently develop in solid state chemistry (especially phase diagrams study) and in thin films growth and structural characterization field, in particular focused on oxides and metals deposited by pulsed laser deposition and sputtering, for various applications (molecular grafting process, microwaves and environmental applications). She is the co-author of 60 papers in these fields. 
Andre Perrin got the PhD degree in chemistry in 1968 and in physics in 1977 from the University of Rennes (France). He was appointed by the CNRS as researcher from 1968 to 1990 and then as Research Director, at the University of Rennes. He was involved in solid state chemistry, especially the synthesis and structure of octahedral $\mathrm{Re}_{6}$ cluster chalcohalides and the growth and structural characterisation of thin films of various materials, including Chevrel phases, HTc superconductors and more recently ferroelectric oxides. He is the co-author of about 200 papers in these fields.

Jean-Pierre Guin received the PhD degree from the University of Rennes (France) in 2001. From 2002 to 2005, he was appointed as a guest researcher at the National Institute of Standards and Technology (NIST, USA). Currently, he is a CNRS researcher at LARMAUR laboratory from the University of Rennes. He is in charge of the glass surface damage, aging and mechanical durability research activity. Specialist in scanning probe microscopy, his research focuses on the study of fracture, permanent deformation and durability of glasses at the nanometer scale. $\mathrm{He}$ is the author and co-author of 30 papers, 2 patents and 50 conferences. 